\title{
Reengineering the Cardiac Catheterization Lab Processes: A Lean Approach
}

\author{
Venkatesh A. Raghavan ${ }^{1}$, Vikram Venkatadri ${ }^{1}$, Varun Kesavakumaran', \\ Shengyong Wang 2,*, Mohammad Khasawneh ${ }^{1}$, and Krishnaswami Srihari ${ }^{1}$ \\ ${ }^{1}$ P.O. Box 6000, Department of Systems Science and Industrial Engineering, State \\ University of New York, Binghamton, Binghamton, New York, 13902-6000, USA \\ ${ }^{2}$ ASEC 101, Department of Mechanical Engineering, \\ The University of Akron, Akron, OH, 44325-3903, USA
}

\begin{abstract}
This paper presents a cross-functional effort in a US community hospital for an overall process improvement in its Cardiac Catheterization Lab (CCL). One of the key system performance metrics identified was the patient turnaround time. The objective of this study was to identify the sources of delays in the system that lead to prolonged patient turnaround time using a structured lean approach. A set of qualitative recommendations were proposed and implemented. Quantification of some of these recommendations and certain additional 'what-if' scenarios were evaluated using Discrete Event Simulation (DES). The simulation results showed that significant reduction in patient turnaround time could be achieved if the proposed recommendations were implemented. This study demonstrated the benefits of adopting the lean philosophy in the continuous process improvement journey in the healthcare delivery arena.
\end{abstract}

Keywords: Reengineering, lean techniques, cardiac catheterization lab, patient turnaround time

\section{INTRODUCTION}

Cardiac Catheterization is an important procedure involving insertion of a long, thin, flexible tube (catheter) into a blood vessel in the groin (upper thigh) or arm of the patient. The catheter is then threaded all the way to the heart to perform diagnosis or to provide treatment [1]. The heart and blood vessels are monitored using special dyes injected through the catheter for X-ray imaging. Thus, narrowing or blockages of the coronary arteries can be identified and treated [1]. Electro Physiology (EP), a slightly different cardiology subspecialty, is the study of electric flow through the heart. A problem along this electric pathway, known as arrhythmia, needs to be treated if serious. Certain heart tissues could result in 'short-circuiting' the desired electric flow, causing arrhythmia in patients [2].

Advances in the treatment of coronary artery disease have substantially increased the average life expectancy in developed nations over the past few decades. Percutaneous coronary intervention provides a less invasive alternative for coronary artery bypass

*Corresponding Author: Shengyong Wang, wangs@uakron.edu 
grafting for the treatment of acute myocardial infarction and unstable angina. While some cases in the Cardiac Catheterization Lab (CCL) are elective and thus scheduled in advance, the flow of the day is always subject to interruption by emergencies, in particular ST-elevation myocardial infarctions. A properly planned process is needed for the CCL on any particular day to be capable of not only treating emergency patients in a timely manner, but also treating all patients through a cost effective process.

In this study, a CCL in a community hospital, where two types of procedures, Cardiac Catheterization (CC) and Electro Physiology are performed, was studied for continuous process improvement. Both CC and EP labs interact with a 13-bed Cardiac Ambulatory Care Unit (CACU) that prepares outpatients before medical procedures. For inpatients, the interaction is with the inpatient wards. Each day, a 'Doctor of the Day', an interventional cardiologist, takes care of the procedures for that day. The limited number of resources (e.g., nurses, beds) at the CACU coupled with its shared use with the radiology department patients poses a challenge to the CCL system in turning patients around in a timely manner.

This research focuses on adopting a systematic approach of continuous process improvement in the CCL and identifying areas which would help reduce the key performance measure of patient turnaround time. A lean approach was adopted to achieve this research objective. Parameters such as patient wait time at the CACU, patient transfer time and inter-procedural delays were studied. 'Lean' is an approach that aims at "getting the right things to the right place at the right time in the right quantity to achieve perfect workflow while minimizing waste and being flexible and able to change" [3]. It involves identifying and eliminating non-value added steps in a process for improving the efficiency of the process at decreased costs [4]. The lean approach has been used in this work since the system under study consisted of several processes where identification and elimination of non-value added activities are possible.

The remainder of the paper is organized as follows: Section 2 reviews the related literature and discusses the uniqueness of this research. Section 3 presents the methodology implemented for continuous process improvement. The system is delineated using process mapping and the data collection process is explained. In Section 4, after analyzing the sources of delays in the system using Cause and Effect Diagram and Value Stream Maps, the findings and recommendations for reducing the delays and decreasing the overall patient turnaround time are summarized. Finally, Section 5 discusses the limitations, future work and concludes this paper with final remarks.

\section{LITERATURE REVIEW}

Healthcare delivery costs continue to rise due to increased demand for patient services. Various hospital departments, such as the emergency department (ED), radiology department, CCL, and pharmacy represent a small sample of such departments facing high patient demand. On the other hand, there exist tremendous opportunities for cost reduction and quality improvement in the operation of these departments. This section 
reviews some of the lean techniques and other process improvement approaches that have been adopted in the healthcare sector.

In practicing Business Process Reengineering (BPR), changes can be brought about to a system only after the existing processes are fully understood [5]. To this end, process mapping and work flow diagramming can be applied to achieve a better understanding of the work process and the entire system. To illustrate the benefits provided by some of these methods, process mapping in particular has been used as a tool at a medical centre, to identify value streams and differentiate those patients who were potential inpatients from those who would be discharged soon after their ED visits [6]. Streaming of patients on this basis into two queues reduced patient wait times where the percentage of patients waiting for a minimum of 8 hours prior to admission dropped from $21 \%$ to $19.6 \%$. Flowcharts and spaghetti diagrams, representing other methods of process mappings, can also help identify core processes based on Patient Value Add (PVA) or Business Value Add (BVA), and concentrate more on reducing wastes in these core processes [4].

The method of $5 \mathrm{~S}$ is an important lean technique, which represents a very simple and effective way of keeping organizations efficient. It involves the steps of Sort, Set in order, Shine, Standardize, and Sustain, all achieving the goals indicated in the meaning of these words, which, for example, have afforded reduction in infections at the surgical site at the VA Pittsburgh Health System [4].

Operations Research (OR) techniques such as queuing theory have also been used to solve waiting time problems [7]. Usual methods followed in considering a queue include First In, First Out (FIFO), Last In, First Out (LIFO), or on a priority-basis [8]. Simulation is a common approach and is increasingly applied to healthcare [9]. One study applied simulation to patient admission scheduling and resulted in a reduction in patient wait time when sharing a common resource, such as X-ray room, Computed Tomography (CT) scan area and Intensive Care Unit [10].

Replacing radiology film imaging with digitized archiving system at CT scan area of a healthcare provider, thereby requiring changes to system workflow, helped in maximizing throughput using simulation as a tool [11], where throughput in this context is defined as the number of patients serviced in a given period of time. A lean six-sigma approach was taken in a radiology department to improve the CT scan process as well as to increase the service capacity [12]. Improving the quality of CT scan service through simulation by introducing additional CT equipment was the motive behind another study [13].

Continuous feedback can help in close monitoring and constant improvement of a system. Monitoring a healthcare system from the perspectives of growth, business, patients, and finance are important to keep the system at its best [8]. This essentially forms a part of both the 'Improve' and 'Control' phases in the Define, Measure, Analyze, Improve, and Control (DMAIC) model. Lack of coordination and information sharing can lead to extended patient wait times [14]. Data collection based on patient demand by the hour, day and month, and meeting this demand by proper staffing can help in improving patient flow [15], and reducing the cost of lost opportunity by patients walking away due to overcrowded hospital departments. 
The CCL holds a significant position in generating revenue for a healthcare facility. An extensive review of process improvement research in CCLs is conducted to clearly demonstrate the significance and uniqueness of the research presented in this paper. A study of the CCL revealed long waiting times and delayed start of the first procedure for each day [16]. Lean flow chart methods and value stream maps were developed to identify causes for delays and to improve the process. Frequent occurrence of overtime hours for the CCL is common in today's hospitals, which was observed in a hospital where overtime issues were attributed to the variability in the number of elective patients (non-urgent cases) attended to each day [17]. Data analysis and queuing theory were applied to alleviate the issue by using separate rooms for elective and non-elective cases, depending on the day of the week. A web-based cardiac catheterization quality improvement toolkit called ACC-CathKIT, developed by the American College of Cardiology (ACC) and the Society for Cardiovascular Angiography and Interventions (SCAI), stresses the importance of Continuous Quality Improvement (CQI) and has helped hospitals provide increased cardiac care to patients and realize cost benefits [18]. The CQI program was used to take effect in reducing the outcome variations in the performance of Percutaneous Coronary Intervention (PCI) [19]. A study applied sixsigma method to improve the starting time of the first case every day by restricting the scope from the time a patient entered the hospital until the patient entered the CCL [20].

Despite all these attempts, healthcare issues and undesirable outcomes are still prevalent. The current work focuses on implementing process improvement methodologies in a CCL. The combination of lean techniques and discrete event simulations to improve the CCL processes makes this research unique and significant. The present research went beyond the approach of [20] to further identify and address areas of improvement during the non-medical processes within the procedure rooms, such as table preparation for the next procedure and staffing of registered nurses inside the CCL during the procedure. Process maps and value stream maps were developed for both the whole system as well as isolated sub-systems. The system under study consisted of both inpatient and outpatient procedures. Different process maps were developed for each of these procedures, in addition to a process map for the entire system.

\section{METHODOLOGY}

The research methodology employed in this work to identify improvement areas and to make implementation recommendations for the overall CCL system involved two phases. Phase I included the five stages of the six-sigma approach consisting of the DMAIC methodology to identify potential areas of improvement and to suggest recommendations aiming at an overall process improvement, shown as follows:

1. Define: Study and understand the existing CCL system (Section 3.1.1).

2. Measure: Develop process maps (Section 3.1.2) and conduct time studies and collect all relevant system related data (Section 3.1.4).

3. Analyze: Analyze the collected data by statistical tests (Section 3.1.6).

4. Improve: Use Industrial and Systems Engineering tools such as cause-effect diagram and value stream maps to identify potential causes of delay in the existing 
system (Section 4.1) and make recommendations for continuous process improvements (Section 4.2).

5. Control: Ensure that the recommendations are implemented and followed methodically. This was achieved by discussing with subject matter experts after the recommendations had been implemented one after another.

Phase II dealt with result quantification using discrete event simulation, which included the following steps: 1) Development and validation of a baseline discrete event simulation model which reflects the existing CCL system, 2) Testing of alternate scenarios and measurement of performance outcomes, and 3) Suggesting the best and most feasible solution.

\subsection{System description}

The CCL system under study, which is in the Wilson Memorial Regional Medical Center, Johnson City, New York, operates from 6:00 AM until 3:30 PM on all weekdays, with the procedure for the first patient scheduled to start at 7:30 AM. The CCL physicians are capable of performing procedures for three categories of patients: inpatients, outpatients, and emergency patients. The CCL functions on an on-call basis during other times of the day and on weekends, handling only emergency cases.

\subsubsection{System definition}

The scope of the system is defined in Figure 1. Diagnostic and interventional procedures are the two major procedures conducted in the CCL, whereas the five important procedures conducted in the EP Lab (EPL) are pacemaker installation/replacement, generator replacement, Implantable Cardiac Defibrillators (ICD) implant/battery change, ablation and tilt test. The different resources utilized in the system are provided in Table 1.

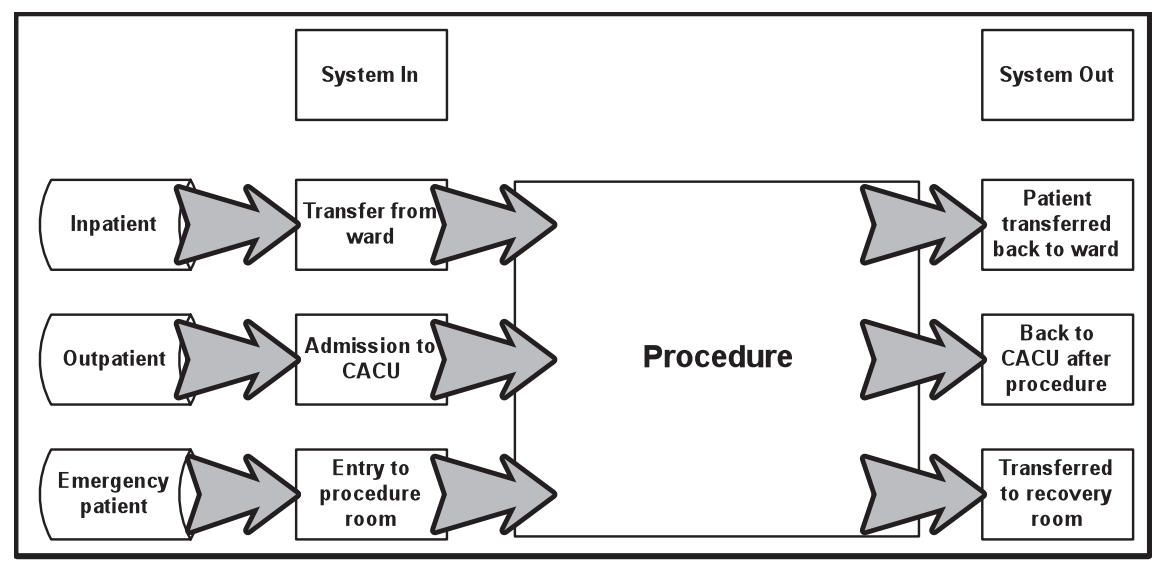

Figure 1. System definition. 
Table 1. Resource availability in the system.

\begin{tabular}{cc}
\hline Resource Name & Quantity of Resource \\
\hline Physician & 6 Interventional Cardiologists* \\
& $\mathbf{3}$ Diagnostic Cardiologists \\
Scrub (Registered Technologist) & $\mathbf{7}(5$ in CCL +2 in EPL) \\
"Circulator" and "Monitor" (Registered Nurse) & $\mathbf{9}(6$ in CCL +3 in EPL) \\
Coordinator (Registered Nurse) & $\mathbf{1}$ \\
Nurse Manager (Registered Nurse) & $\mathbf{1}$ \\
CT scan facility & $\mathbf{3}(\mathrm{CT} 1$ and CT3 in CCL, CT2 in EPL)
\end{tabular}

*2 of these physicians also have the privilege of performing procedure in the EPL.

\subsubsection{Process mapping}

The overall process map for the system is displayed in Figure 2, showing the flow through different processes along with their corresponding departments. In order to better understand the complex nature due to the differences in process flows among outpatients, inpatients, and emergency patients, individual process maps were developed for each type of patients.

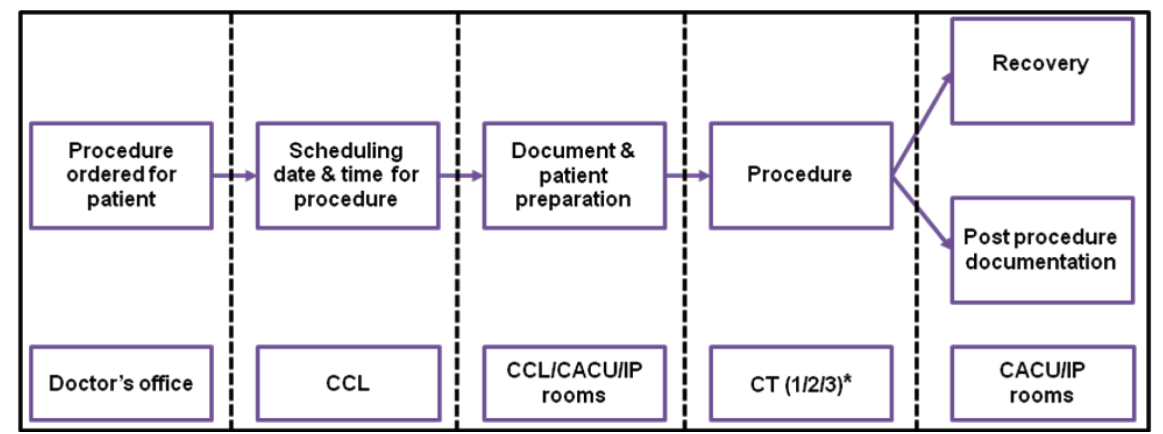

Figure 2. Process map for the overall system (*CT1 and CT3 are in CCLs; CT2 is in EPL).

\subsubsection{Outpatient process flow}

The arrival of the first outpatient to the CACU is scheduled at 6:00 AM to allow preprocedure documentation and medication. Other outpatients for the day are not given specific procedure start times; instead, they are asked to check-in one to two hours before the tentative procedure start time. Only the first procedure of the day is scheduled to start at 7:30 AM. Other procedures will follow one after another, as the time duration for each procedure varies. However, certain physicians require their patients to come to the $\mathrm{CACU}$ at 6:00 AM irrespective of the estimated procedure time. Figure 3 shows the process map for outpatients. Occurrence of the scenario to call off a procedure owing to abnormal lab results is extremely rare, and no such instance was 
observed during the period of study. Hence, this scenario was not considered in this research.
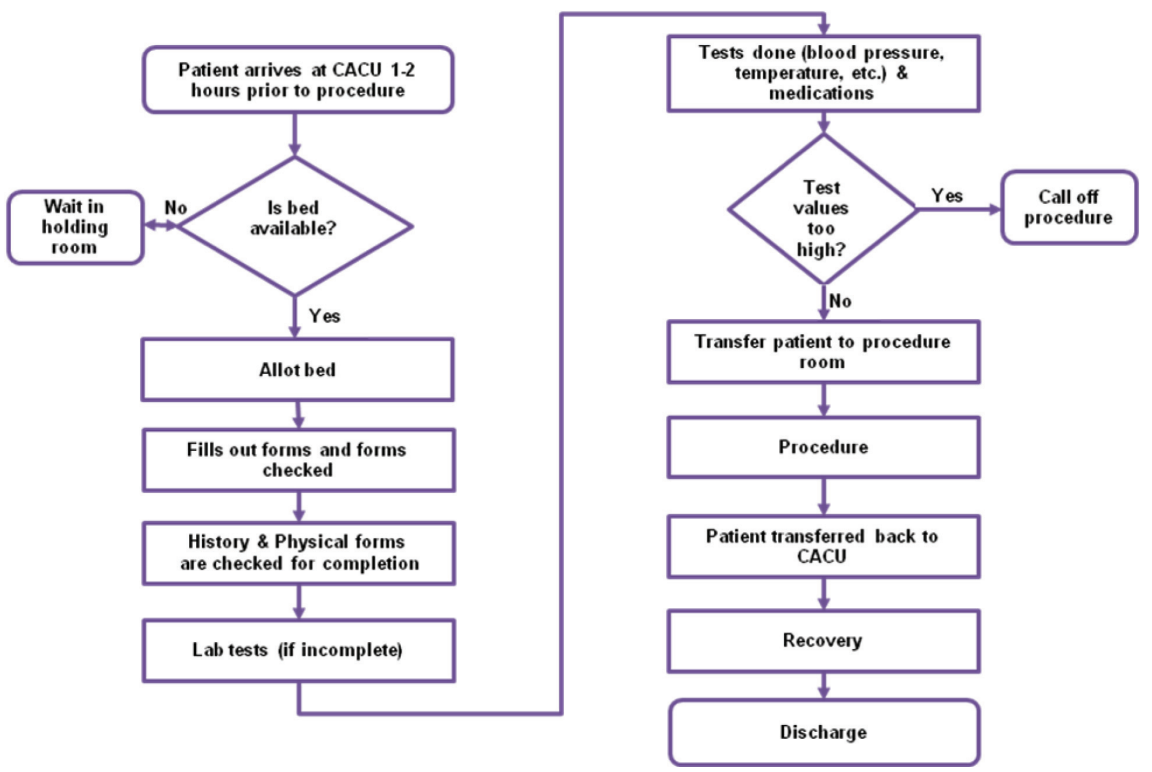

Figure 3. Process map for outpatient flow.

3.1.2.2 Inpatient and emergency patient process flow

The pre-procedure documentation and medication for inpatients take place in the inpatient ward. The floor nurse is responsible for pre-procedure tests, medication, and preparation of the inpatient before they can be transferred to the CCL. It is important to note that the emergency patient has the highest priority among the three types of patients. Emergency patients can enter the system either from the emergency department of the study hospital or from the emergency departments of nearby hospitals. Information regarding the arrival of an emergency patient from a nearby hospital is communicated via telephone to the hospital and CCL authorities. 'Add-Ons' in the system refer to either inpatients or outpatients scheduled for a procedure only on the day of the procedure following their corresponding process flow. Figure 4 depicts the process flow for inpatients and emergency patients.

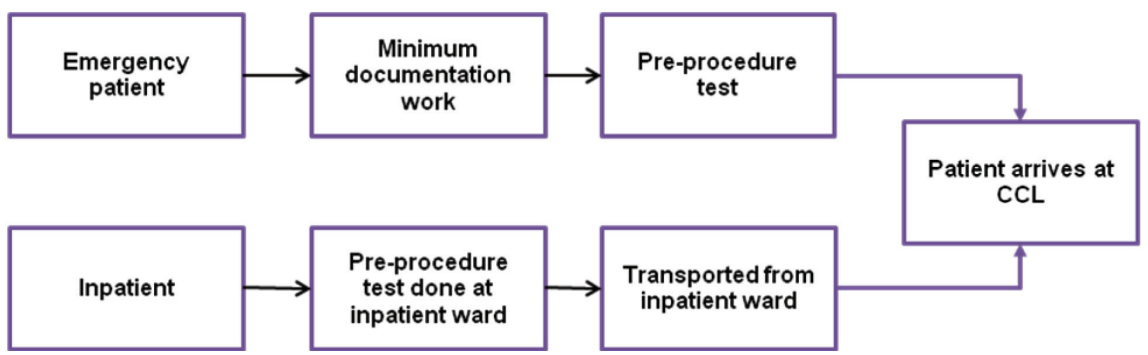

Figure 4. Process map for inpatient and emergency patient flow. 
3.1.2.3 Inpatient transfer from ward: A magnified view

Figure 5 provides a detailed representation of inpatient transfer from the floor to the procedure room, in order to capture any potential delays during the process.
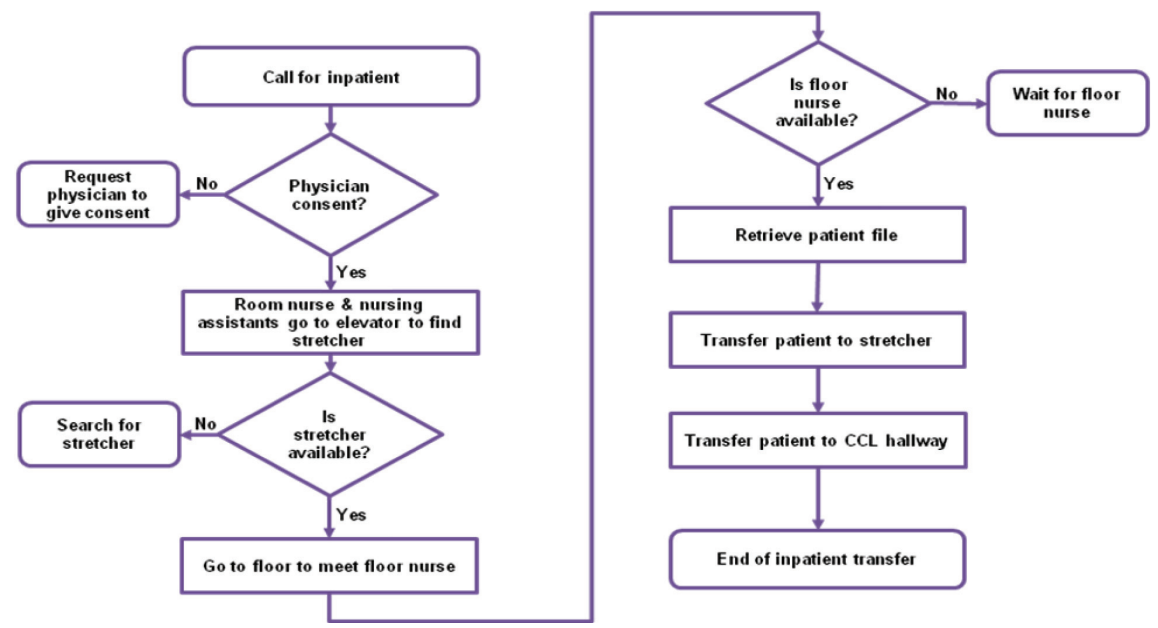

Figure 5. Details of inpatient transfer process flow.

\subsubsection{Procedure process flow}

Figure 6 depicts the processes involved in the cardiac catheterization procedure from procedure room preparation to patient recovery.

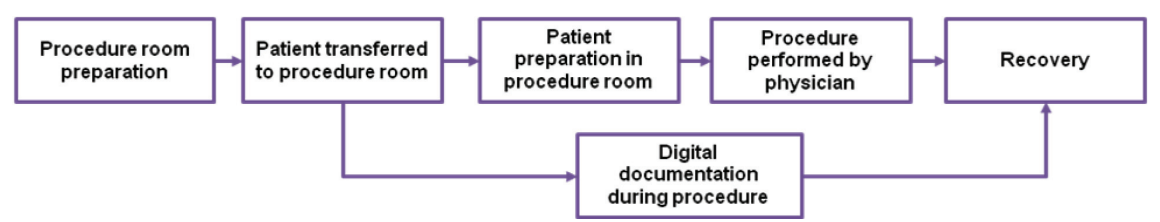

Figure 6. Process map for the cardiac catheterization procedure.

\subsubsection{System resources}

While Table 1 describes the overall system resources, the different process-wise resource requirement is listed below:

Outpatient transfer to and from CACU: One registered nurse and one nursing assistant are needed during this transfer process.

Inpatient transfer to and from floor/ward: This process requires one registered nurse and one nursing assistant.

CCL (CT1 and CT3 procedure rooms): Each of the CCL procedure room is a resource in the system. Other resources involved in a procedure are one physician, one registered technologist and two registered nurses including one "circulator" and one "monitor". The "circulator" is the registered nurse who assists the physician and the 
registered technologists during the procedure. The "monitor" is the registered nurse responsible for the digital documentation during the procedure.

EPL (CT2 procedure room): The EPL is also a resource of the system. Other resources involved during a procedure include one physician, one registered technologist and three registered nurses (one nurse, one "circulator", and one "monitor").

\subsubsection{Data collection}

Data in six major categories were collected in the time study: patient information, staff information, pre-procedure time study, procedure time study, post-procedure time study, and procedure information. A data collection form was created for this purpose and data were collected for one month. Three months of historical data from the hospital archives, along with data collected through data collection form, were then converted into an electronic format. Archival data for a total of 403 patients over a three-month period were analyzed. Table 2 lists the numbers of inpatients, outpatients, and emergency patients' data collected from archives for three months and time-study for one month.

Table 2. Patients' data collected from archives and time-study.

\begin{tabular}{cccccc}
\hline & & Inpatient & Outpatient & Emergency & Total \\
\hline \multirow{3}{*}{ Archives } & Month 1 & 45 & 94 & 15 & 154 \\
\cline { 2 - 6 } & Month 2 & 35 & 59 & 14 & 108 \\
\cline { 2 - 6 } & Month 3 & 55 & 65 & 21 & 141 \\
\hline \multicolumn{2}{c}{ Time Study } & 35 & 38 & 3 & 76
\end{tabular}

\subsubsection{Time study versus archival data validation}

To validate the data available in the department's archives, a paired $t$-test was conducted to test the differences in procedure time data between time study and archives for the same patient in the same period of time. The result showed that the difference in procedure time was not statistically significant at a $95 \%$ confidence level with a $p$-value of 0.316 , therefore indicating that data obtained from archival records could be used for further analysis.

\subsubsection{Data analysis}

Month-wise diagnostic versus interventional procedure time. A two-sample t-test was conducted to check statistical differences in the diagnostic and interventional procedure times for three months. The results exhibited in Figure 7 show that the difference in diagnostic and interventional procedure times is statistically significant at a $95 \%$ confidence level for all three months. The outliers in the box plot indicate the variability in the procedure time, with higher variability for interventional procedure time due to the various procedure complexities involved from patient to patient. Table 3 exhibits the $t$ values and $p$-values generated through a two-sample $t$-test for the month-wise comparisons between the diagnostic and interventional procedures. However, from month to month, the difference within each procedure type (diagnostic or interventional) is not statistically significant. 


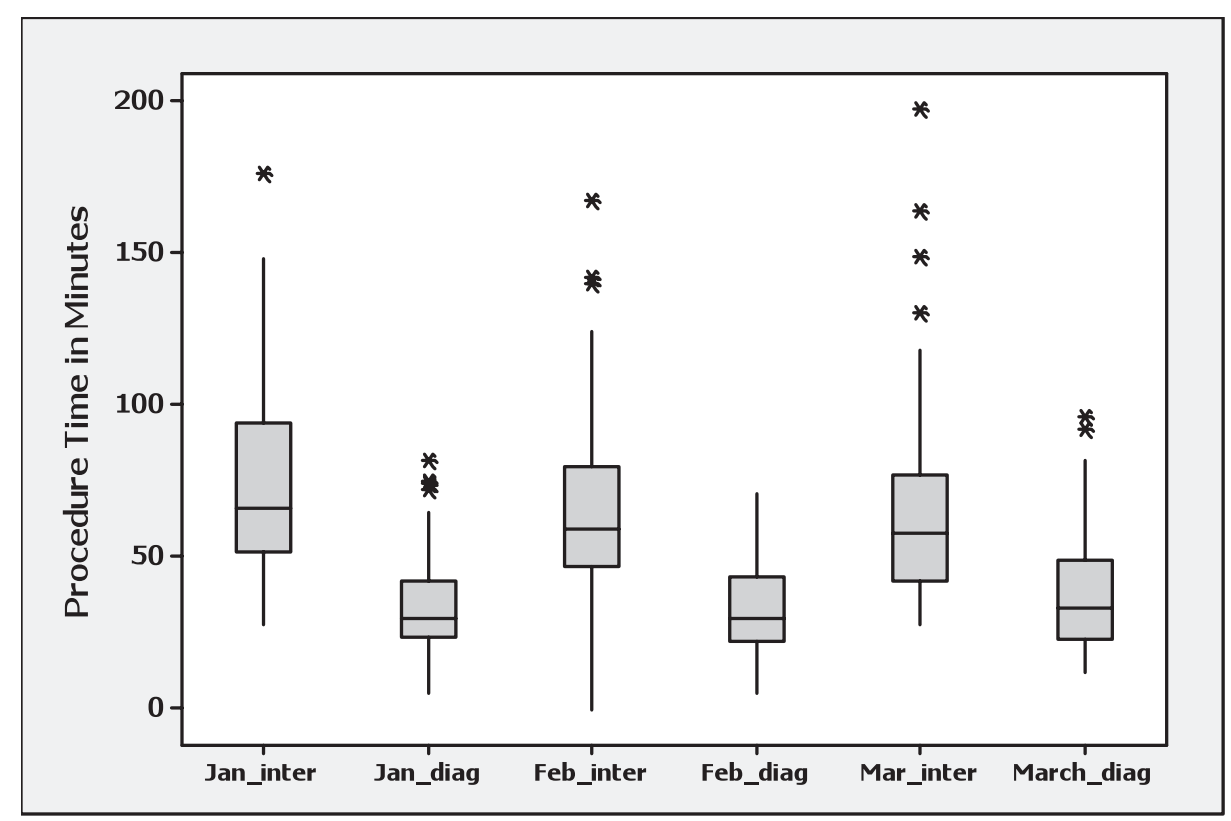

Figure 7. Comparison of diagnostic and interventional procedure times for 3 months. [* indicates outlier]

Table 3. $t$-values ( $p$-values) for the month-wise comparisons of diagnostic (Diag) and interventional (Inter) procedure times.

\begin{tabular}{|l|cccccc|}
\hline & \multirow{2}{*}{ Jan_Inter } & Jan_Diag & Feb_Inter & Feb_Diag & Mar_Inter & Mar_Diag \\
\cline { 2 - 7 } & $9.7(0)$ & $0.69(0.49)$ & $9.49(0)$ & $0.9(0.37)$ & $8.41(0)$ \\
\hline Jan_Inter & & $-6.38(0)$ & $0.01(0.99)$ & $-6.72(0)$ & $-1.25(0.21)$ \\
\hline Jan_Diag & & & $6.31(0)$ & $0.14(0.89)$ & $5.61(0)$ \\
\hline Feb_Inter & & & & $-6.63(0)$ & $-1.19(0.24)$ \\
\hline Feb_Diag & & & & & $5.85(0)$ \\
\hline Mar_Inter & \multicolumn{7}{c}{} \\
\hline Mar_Diag & \multicolumn{7}{c}{} \\
\hline
\end{tabular}

Physician-wise procedure time comparison. Figure 8 shows that the difference in procedure time among different physicians is not statistically significant at a $95 \%$ confidence level. Results of a two-sample $t$-test conducted among the procedure times of different physicians are summarized in Table 4 which provides the $t$-values and $p$ values of the comparison tests. The results suggest that physicians do not have an impact on procedure time and, hence need not be considered individually. The outliers in the box plot indicate expected variability because of the complexities involved in the procedure which vary among patients. Figures 7 and 8 therefore indicate that the procedure time is dependent on the type of the procedure but not on the individual physician. 


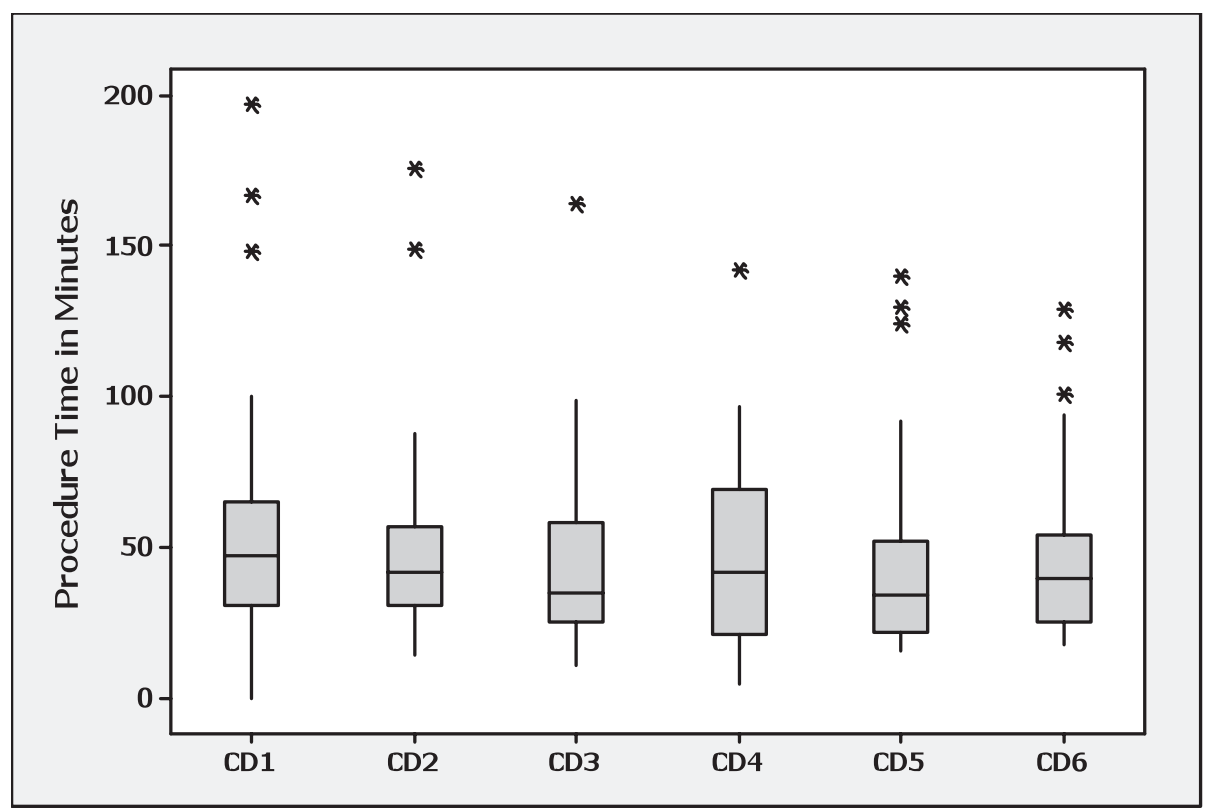

Figure 8. Comparison of physician-wise procedure time $(\mathrm{CD} 1, \mathrm{CD} 2, \ldots, \mathrm{CD} 6$ are the 6 interventional cardiologists). [* indicates outlier]

Table 4. $t$-values ( $p$-values) for the physician-wise procedure time comparison.

\begin{tabular}{|l|l|lllll|}
\hline \multicolumn{2}{|c}{ CD1 } & \multicolumn{1}{c}{ CD2 } & \multicolumn{1}{c}{ CD3 } & \multicolumn{1}{c|}{ CD4 } & \multicolumn{1}{c|}{ CD5 } & \multicolumn{1}{c|}{ CD6 } \\
\hline CD1 & & $1.08(0.283)$ & $2.6(0.01)$ & $0.74(0.46)$ & $1.89(0.06)$ & $1.08(0.28)$ \\
\hline CD2 & & & $1.32(0.19)$ & $-0.11(0.91)$ & $0.91(0.37)$ & $0.18(0.85)$ \\
\hline CD3 & & & & $-1.11(0.27)$ & $-0.15(0.88)$ & $-0.86(0.40)$ \\
\hline CD4 & & & & $0.85(0.40)$ & $0.25(0.80)$ \\
\hline CD5 & & & & & $-0.61(0.54)$ \\
\hline CD6 & & & & & \\
\hline
\end{tabular}

Procedure time data analysis. The data collected show that a large percentage of inpatients undergo interventional procedures while a large portion of outpatients undergo diagnostic procedures. There is a significant difference in the procedure time for emergency patients. Moreover, in the system, the type of procedure and procedure time at the CCL is unknown until the procedure is performed. However, in the EPL, the procedure time is related to the type of procedure rather than the patient type. This analysis was useful for identifying proper statistical distributions in creating the discrete event simulation model for exploring alternative ways to improve the system performance. 


\section{RESULTS AND DISCUSSIONS}

\subsection{Identification of sources of delay in the system}

Causes for delay in the system were identified using a Cause and Effect (C\&E) diagram and Value Stream Maps (VSMs).

\subsubsection{Cause and effect diagram}

Figure 9 shows the C\&E diagram with the "causes" highlighted in red indicating potential areas for improvement in the process. This diagram was developed taking into account all types of patients and including all possible causes of delays in different processes in the system.

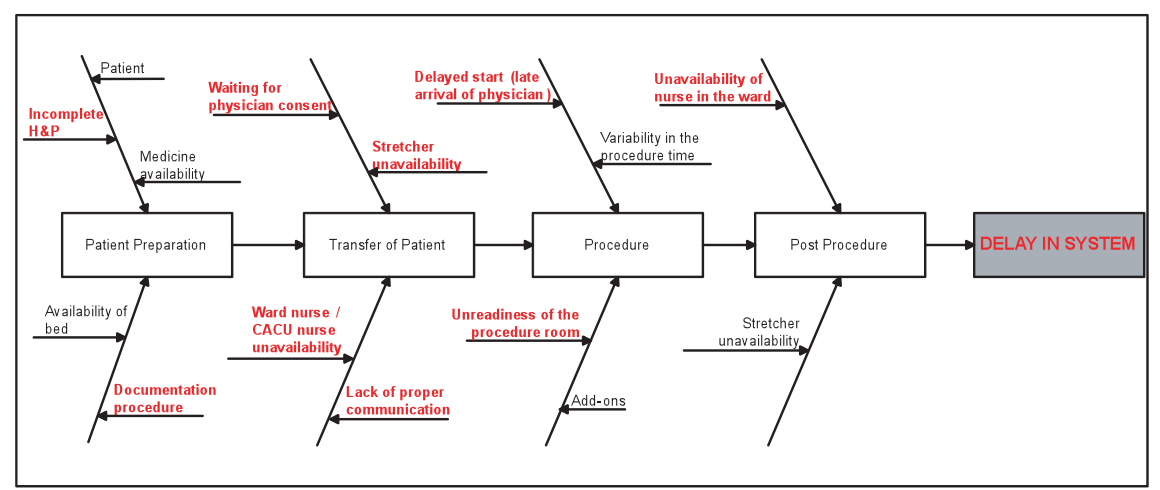

Figure 9. Cause and effect diagram for delays in the system.

\subsubsection{Value stream maps}

VSMs were developed for the overall inpatient flow (Figure 10), details of the inpatient transfer process from the inpatient ward/floor (Figure 11), and the overall outpatient flow (Figure 12). Figure 11 was developed to provide further details observed in Step 1 in Figure 10, and includes activities to assist the transfer of an inpatient from the ward. Hence, the total time covered in Figure 11 would be longer than that observed in Step 1 in Figure 10. VSMs were not developed for emergency patients because it was observed that the overall process in sending such a patient into the procedure room occurred in a very short period of time. This short duration from the time a patient arrives at the hospital to the time the angioplasty balloon is inflated in the blocked artery of the patient is known as the "door-to-balloon" time and should be under 90 minutes according to the guidelines [21]. Observations and discussions with the subject-matter experts indicated that the door-to-balloon time was well within the 90 minute time frame. Moreover, there was practically no non-value added activity involved in the treatment of emergency patients, leaving little room for improvement in this process. 


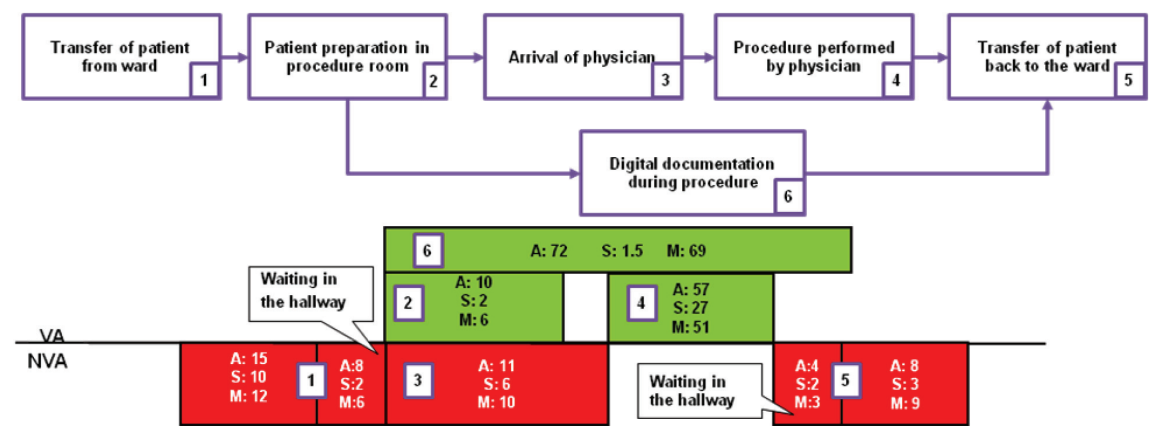

Figure 10. Value stream map for inpatient process flow (VA: Value-added activities; NVA: Non-value-added activities; A: average; S: standard deviation; M: median. Data are in minutes).

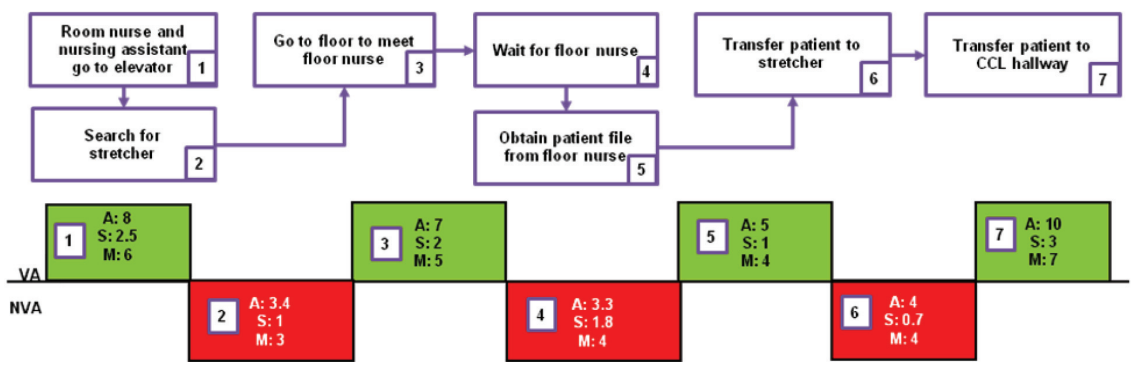

Figure 11. Value stream map for inpatient transfer from inpatient ward. (VA: Valueadded activities; NVA: Non-value-added activities; A: average; S: standard deviation; M: median. Data are in minutes).

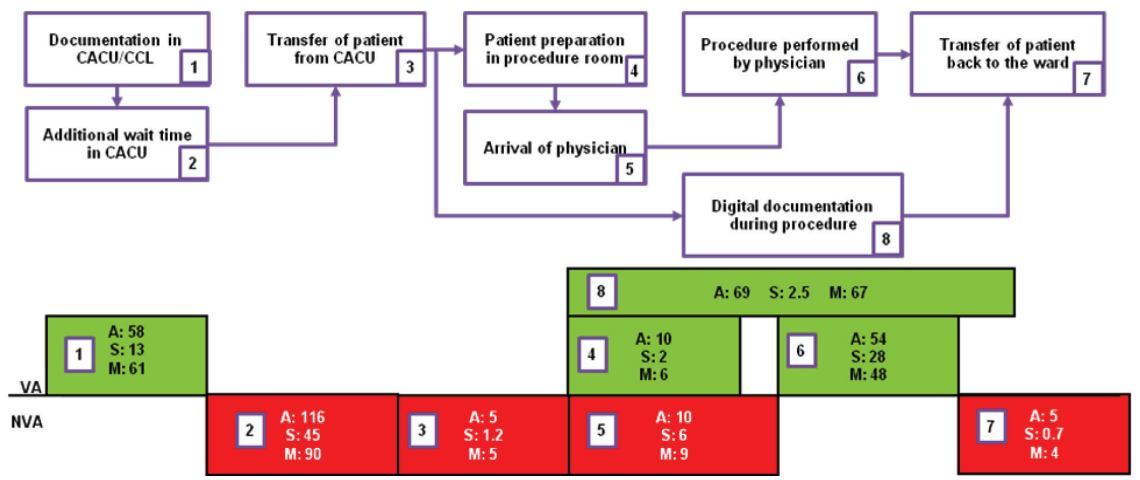

Figure 12. Value stream map for outpatient process flow. (VA: Value-added activities; NVA: Non-value-added activities; A: average; S: standard deviation; M: median. Data are in minutes). 
Based on the data collected, C\&E diagram, and VSMs, the following sources of delay in the system were identified:

1. Delayed start of procedure

a. First procedure for the day starts at 8:07 AM (on average).

b. Late arrival of physician to procedure room.

c. Inter-procedure delays.

2. Patient waiting time delays

a. The time outpatients waiting in CACU between the pre-procedure documentation and being sent into the procedure room averages about 116 minutes with a standard deviation of 45 minutes (Figure 12).

b. Patients waiting in the inpatient ward or CACU for the physician's consent. The consent is mandatory for a procedure to begin.

3. Delays in transferring patients to and from the procedure room

a. Unavailability of stretcher for transferring inpatients.

b. Lack of proper communication between the CCL staff and the ward nurse.

c. Patient waiting in the hallway in front of the CCL.

\subsection{Recommendations for reducing the delays}

The recommendations towards process improvements are broadly classified as qualitative and quantitative. Techniques such as the lean $5 \mathrm{~S}$ principle and modified workflow diagram were part of the qualitative approach. Discrete event simulation was applied as a quantitative approach to quantify the reduction in delays throughout the system. The research team worked very closely with cardiologists, nurse manager, registered nurses, technologists, ward nurses, and the special projects director during the study. This took place in the form of interviews, discussions, brain-storming sessions, periodic review meetings and presentations to ensure the success of the study and the acceptance and implementation of recommendations and/or suggestions.

\subsubsection{Qualitative approach}

One of the major causes of delays in transferring an inpatient from the floor was the unavailability of stretchers. Dedicated stretchers were not available in the CCL since there was not enough parking space. In addition, some medical supplies for the cardiac catheterization procedures were stocked in the hallway, leading to multiple congestions. The research team studied the existing layout and implemented the lean $5 \mathrm{~S}$ principle. Figure 13 shows the existing layout of the CCL and Figure 14 shows the modified layout. The following were the series of steps taken to achieve the objective.

1. Sort: As part of sorting, the existing lead apron stand, occupying one third of the hallway width, was replaced with a wall-mountable version. This reduced the congestion in the hallway. The board displaying the patients and doctors for a particular day was also moved to a much better position, as shown in Figure 14 (modified layout).

2. Set in order:

a. In addition to the lead apron stand, the hallway was further congested by the 
stocking of medical supplies (e.g., catheters). A study of the rooms that belonged to the CCL showed that the present nursing assistant room was not properly utilized. Also, this room being close to the procedure room would be ideal for storing the medical supplies. Therefore, it was suggested to stock the lab supplies in the present nursing assistant room instead of the hallway to solve the hallway congestion problem and to improve access to supplies from the procedure room.

b. Re-allocation of rooms for nursing assistants and the nurse manager were also suggested.

3. Shine: The entire area was cleaned regularly, especially the room where the supplies were stocked. For the purpose of setting up the procedure room table for the next procedure in an orderly manner and to further improve the process, available technologists were suggested to be responsible for arranging the supplies on the table without affecting the hygiene.

4. Standardize: As a standard process, the supplies are now moved directly into the new room identified. A standard practice of two technologists preparing procedure room tables has been implemented. A standard framework, in the form of a Cross Functional Diagram, detailing the responsibilities of the staff and the flow of the overall process was also developed and suggested, as will be discussed later in this section.

5. Sustain: This is the most important part of the $5 \mathrm{~S}$ principle since all efforts would be in vain if the process improvement recommendations are not sustained. At present, the new process is being sustained. Periodic reviews and measurements of various parameters would help in gauging the process before and after the recommendations were in effect. For example, currently no item is stocked in the hallway, following the research team's recommendation that has considerably reduced the congestion.

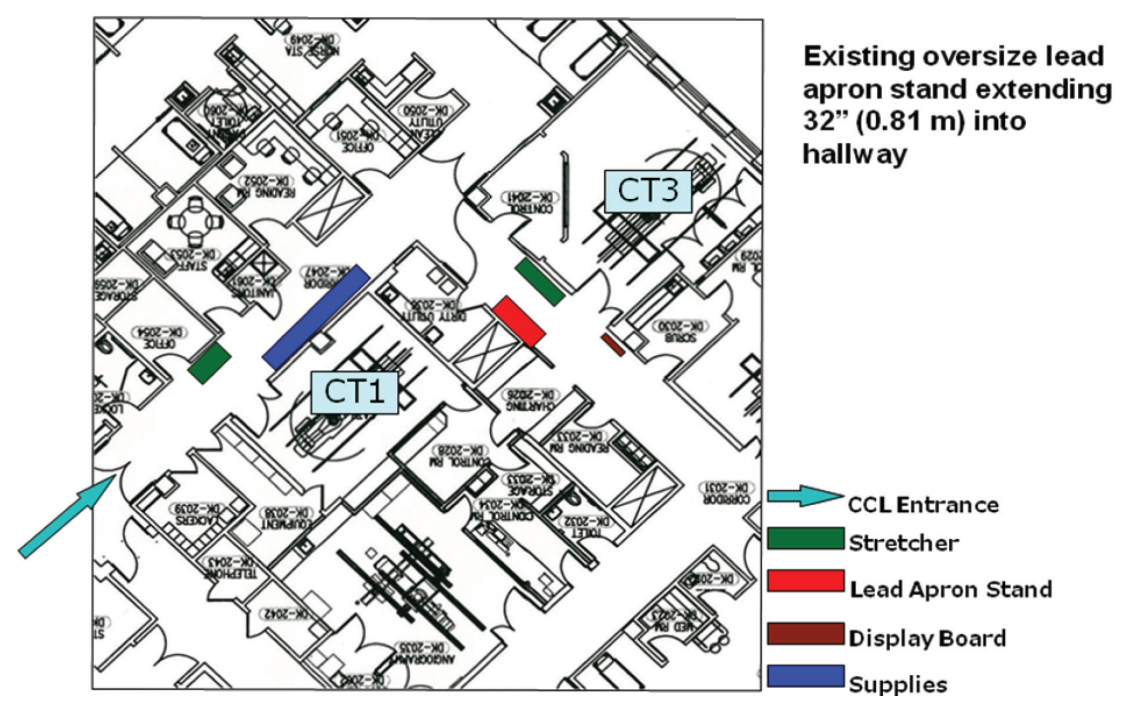

Figure 13. Existing CCL layout. 
Implementation of the $5 \mathrm{~S}$ principle has helped identify a designated parking space for 'permanent stretchers' at the rear entrance of the CACU. This has also helped clear up the hallway and provide temporary parking space for the stretchers while patients were undergoing procedure inside the procedure room.

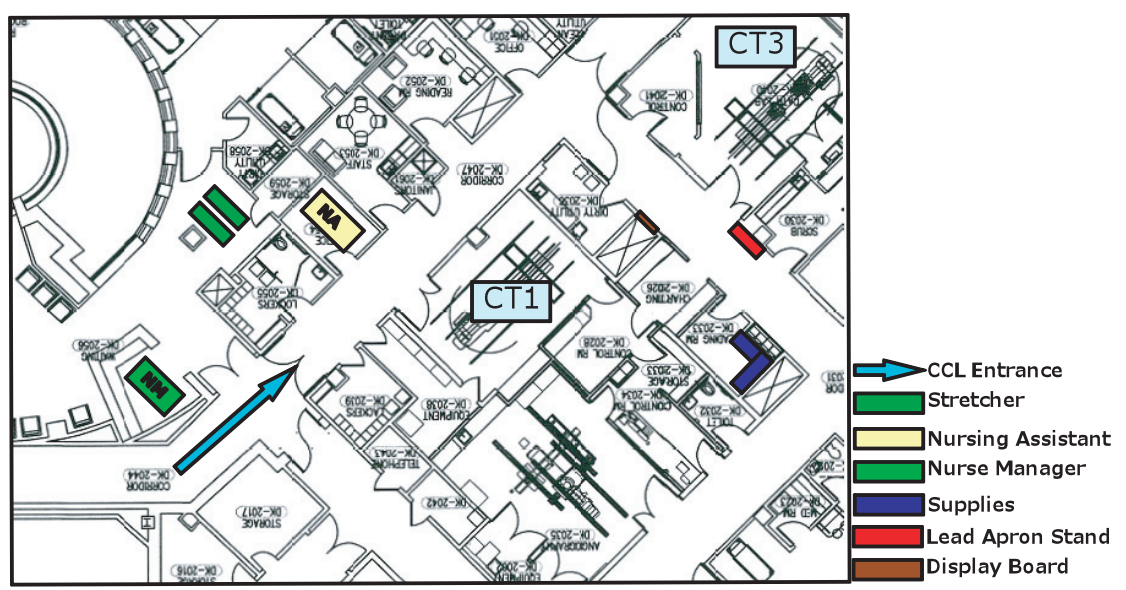

Figure 14. Modified CCL layout.

Table 5 summarizes the qualitative recommendations that have been discussed. Other qualitative recommendations include the following:

1. Transferring inpatients back to the floor after the procedure without waiting for 'call-reports'. Call-reports are reports sent to the CCL from the inpatient ward nurse once the procedure on an inpatient is completed. Delays in inpatient transfer occurred as the CCL waited for call-reports from the floor nurse before transferring the inpatient back to the ward.

2. Effective and proper rotation of the three categories of registered nurses, namely "circulator", "monitor", and "free-nurse". A "free-nurse" is a registered nurse who does not have any designated task to perform during a procedure. Currently, the "monitor", the "circulator", and the "free-nurse" of a procedure take the roles of the "circulator", the "free-nurse", and the "monitor", respectively, in the next procedure. However, a delay is encountered as the "monitor" of a procedure is taking time to complete the post-procedural documentation before being able to assume the role of a "circulator" for the next procedure. This delay can be reduced if the task-rotation cycle is changed so that the "free-nurse" assumes the role of the "circulator" in the next procedure. Without any designated task, the "free nurse" can readily begin his/her role as the "circulator" in the next procedure without delay. Therefore, it is recommended to change the task-rotation cycle so that the "monitor", the "circulator", and the "free-nurse" of a procedure take the roles of the "free nurse", the "monitor", and the "circulator", respectively, in the next procedure. Thus, for a particular nurse, the task cycle from procedure to 
procedure is "monitor" $\rightarrow$ "free nurse" $\rightarrow$ "circulator" $\rightarrow$ "monitor".

3. Using inpatient bed instead of a stretcher to transfer patient to procedure room. In the current system, inpatients are transferred to the procedure room using stretchers by nursing assistants. This process involves lifting and transferring a patient from the inpatient bed onto the stretcher (in the ward), from the stretcher onto the procedure table (in the procedure room), again back onto the stretcher after the procedure (in the procedure room), and finally onto the inpatient bed (in the ward). The use of inpatient beds as stretchers helps reduce the transfer time, mitigate the risks of injuries to the patient as well as the healthcare personnel, and avoid the waste of time on searching for stretchers.

Table 5. Summary of qualitative recommendations.

\section{Qualitative Recommendations}

1. Replacing the existing oversize stand with a wall-mountable apron stand.

2. Stocking medical supplies in nursing assistant rooms instead of hallways.

3. Having additional registered technologists to be responsible for procedure room table preparation.

4. Transferring inpatients to the floor after procedure without waiting for 'call-reports'.

5. Proper rotation of the registered nurses (circulator $\rightarrow$ monitor $\rightarrow$ free-nurse).

6. Use of patient beds to transfer inpatients from ward to procedure room.

Modified workflow - A Cross F unctional Diagram. Based on the comprehensive study of the system, a Cross Functional Diagram (modified workflow, shown in Figure 15) was suggested which defines and includes the duties and responsibilities of each functional category, such as the Registered Technologist, Physician, Registered CCL Nurse, Lab Secretary and Nursing Assistant.

\subsubsection{Quantitative approach}

Discrete event simulation using Arena $10.0^{\circledR}$ was adopted in the present quantitative approach. The existing CCL system was first carefully modeled to form the baseline simulation model. Statistical distributions derived from the collected data were then inputted into the model. These include distributions for the inter-arrival times of the three types of patients, procedure time, preparation time in $\mathrm{CACU}$ for outpatients, physician arrival time, and patient transfer time to the CCL for both inpatients and outpatients. The model was run as a steady-state, non-terminating system for busy days for a total of 40 replications. According to subject matter experts, a day is considered "busy" when there are more than five patients per day. The baseline model was then verified and validated against data collected. The simulation model and the real system performance (collected data) were compared in terms of the throughput (number of patients), a primary output parameter. The differences between the simulation model results and that of the real system were only $0.83 \%$ for emergency patients, $0.73 \%$ for inpatients, and $1.25 \%$ for outpatients. Other parameters, such as procedure time and patient turnaround time, differed only from $2.04 \%$ to $7.78 \%$ between the collected data 


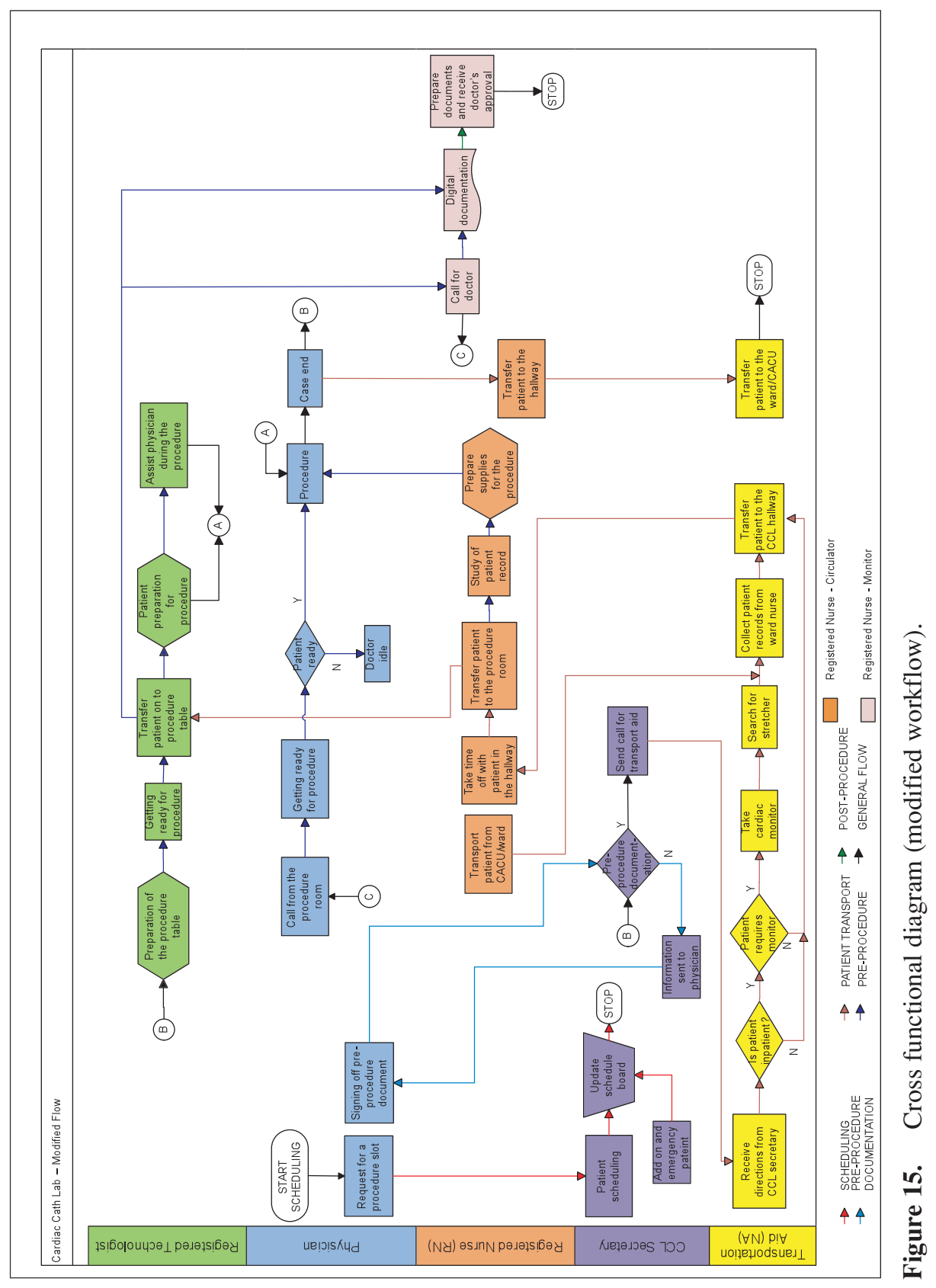


and the model results with the model results on the larger side, suggesting that the baseline simulation model created was a very good representation of the real system.

A Strengths, Weaknesses, Opportunities and Threats (SWOT) analysis was conducted amongst the CCL staff by means of separate survey forms for each of the resources. The survey consisted of questions tailored to suit different stakeholders based on their roles and responsibilities, with the primary goal being to capture their point of views on how the CCL system could be improved. The results of the survey were used to justify the alternative scenarios developed by the research team. Alternative scenarios developed in addition to those recommendations developed from the qualitative approach are listed below:

1. Eliminate delays in starting the first procedure for the day. This meant that the first procedure of the day should start at the ideal time of 7:30 AM.

2. Eliminate delays in physician arrival once the patient is ready in the procedure room, using proper communication channels.

3. Reduce procedure room turnaround time by utilizing the required number of technologists to prepare the procedure room table where all surgical supplies required for the next procedure are placed.

4. Reduce inpatient transfer times to and from the procedure rooms.

These, amongst other combinations of scenarios, were incorporated into the baseline model. Observations of a few selected scenarios are listed in Table 6.

Table 6. Simulation results for selected alternative scenarios.

\begin{tabular}{lll}
\hline & Recommendation & Result \\
\hline 1. & Elimination of inpatient transfer delays & Turnaround time decreased by $44.5 \%$ \\
2. & Reduction of extra waiting time in & Turnaround time decreased by $30 \%$ \\
& CACU for outpatient & Overall procedure end time in CCL \\
3. & Elimination of inter-procedure time & decreased by $16.6 \%$
\end{tabular}

The results in Table 6 show that the turnaround time could be reduced by as much as $44.5 \%$ by eliminating the delays in inpatient transfer. The additional waiting time at the CACU contributes to significant delay in the system. Hence, if this waiting time were reduced, the patient turnaround time could be decreased by $30 \%$. Moreover, by eliminating inter-procedure time delays, the overall procedure end time in CCL could be reduced by $16.6 \%$.

\section{CONCLUSIONS, LIMITATIONS AND FUTURE WORK}

By taking a six-sigma DMAIC approach, coupled with many lean techniques, the areas of continuous process improvement in a hospital's CCL were comprehensively identified. The application of the lean $5 \mathrm{~S}$ principles helped in rearranging and reorganizing the layout of the CCL system. The incorporation of the qualitative 
recommendations brought in a new approach to CCL function and a new dimension to CCL staff's view of the system. The modified workflow diagram helped in setting the roles and responsibilities within the existing flexible framework. Quantifiable results using modeling and simulation have helped convince the management to adopt the lean philosophy in the journey of continuous process improvement.

A plan was proposed to the process owner of the CCL to ensure successful implementation of the recommendations. The plan included integration of the recommendations followed by collection of data over the subsequent quarter. All data related to this research would be collected during that quarter for the same set of metrics developed during the study. The pre- and post-implementation metrics would be compared for statistical significance. Furthermore, the results will also be compared with the output from the simulation model.

This work demonstrated that systematic use of industrial and systems engineering techniques, such as C\&E diagrams and VSMs, can help identify and eliminate nonvalue added activities in the system. Furthermore, a Cross Functional Diagram can help identify not only the flow within the system, but also the designated functions of every category of personnel. This can further be an effective tool helping the management make decision on training, retraining, and (re)allocating staff.

One of the primary limitations of this research is that the time study was only conducted for one month and that only three months of archival data were studied. Future research should involve long-term data to allow capture of variability in patient arrival and treatment over a longer time period. Moreover, analyzing the hospital system from a System of Systems (SOS) perspective could be incorporated into the study. For example, the CACU prepares patients for both CCL and the radiology department. Study on the way patients of either CCL or radiology department affects the preparation times of patients of the other departments can provide insights into whether separate units need to be installed for patient preparation.

\section{ACKNOWLEDGEMENTS}

The authors would like to thank the CCL staff at Wilson Memorial Regional Medical Center, NY, for their cooperation and support in conducting this research. The authors would also like to thank Dr. Sreekanth Ramakrishnan, Advisory Engineering at IBM, and Moh'd El-Sharo, a doctoral student at Binghamton University, NY, for their guidance and support during the course of this research. Finally, the authors would like to acknowledge the anonymous reviewers for their valuable comments and suggestions on the original submission of this paper.

\section{REFERENCES}

1. National Heart Lung and Blood Institute, "Cardiac Catheterization", http://www.nhlbi.nih.gov/health/dci/Diseases/cath/cath what.html, 2009, Accessed July 2009.

2. Heart Rhythm Society, "EP Study", http://www.hrspatients.org/patients/heart tests/ electrophysiology study.asp, 2009, Accessed July 2009.

3. Donald E. Lighter, Advanced Performance Improvement in Health Care: Principles and Methods, Jones \& Bartlett Publishers, Massachusetts, USA, 2009.

4. Chalice, R.W., Stop Rising Healthcare Costs Using Toyota Lean Production Methods, ASQ Quality Press, Milwaukee, Wisconsin, USA, 2005. 
5. Kumar, A. and Shim, S.J., Eliminating Emergency Department Wait by BPR Implementation, Industrial Engineering and Engineering Management: IEEE International Conference, 2007, 1679 1683.

6. King, D.L., Ben-Tovim, D.I. and Bassham, J., Redesigning emergency department patient flows: Application of Lean Thinking to health care, Emergency Medicine Australasia, 2006, 18(4), 391-397.

7. Connelly, L.G. and Bair, A.E., Discrete Event Simulation of Emergency Department Activity: A Platform for System-level Operations Research, Acad Emerg Med., 2004, 11(11), 1177-1185.

8. $\quad$ Eitel, D.R., Rudkin, S.E., Malvehy, M.A., Killeen J.P. and Pines, J.M., Improving Service Quality by Understanding Emergency Department Flow: A White Paper and Position Statement Prepared For The American Academy Of Emergency Medicine, Journal of Emergency Medicine, In Press, Corrected Proof, Available online 2 June 2008.

9. Davies, R. and H. Davies, Modeling patient flows and resource provision in health systems, Omega, 1994, 22(2), 123-131.

10. Hutzschenreuteryz, A.K., Bosmanz, P.A.N. and Blonk-Altenax, I., Agent-based Patient Admission Scheduling in Hospitals, Proceedings of the 7th international joint conference on Autonomous agents and multiagent systems: industrial track, Estoril, Portugal, 2008, 45-52.

11. Ramakrishnan, S., Nagarkar, K., DeGennaro, M., Courtney, A.K., Emick, F. and Srihari, K., A Study of the CT Scan Area of a Healthcare Provider, in: Ingalls, R.G., Rossetti, M.D., Smith, J.S. and Peters, B.A., eds., Proceedings of the 2004 Winter Simulation Conference, Washington DC, USA, 2004, 20252031.

12. Workman-Germann, J. and Woodward-Hagg, H., Implementing Lean Six Sigma Methodologies in the Radiology Department of a Hospital Healthcare System, http://docs.lib.purdue.edu/cgi/ viewcontent.cgi?article=1037\&context=rche rp, RCHE Publications, 2007 (accessed 5 July 2009).

13. Bosire, J., Gandhi, T., Wang, S. and Srihari, K, Comparing Simulation Alternatives Based on Quality Expectations, in: in: Henderson, S.G., Biller, B., Hsieh, M.H., Shortle, J., Tew, J.D. and Barton, R.R., eds., Proceedings of the 2007 Winter Simulation Conference, 2007, Washington DC, USA, 1579-1585.

14. Abraham, J. and Reddy, M.C., Moving Patients Around: A Field Study of Coordination between Clinical and Non-Clinical Staff in Hospitals, Proceedings of the ACM 2008 conference on Computer supported cooperative work, 2008, San Diego, USA, 225-228.

15. Jensen, K. and Crane, J., Improving Patient Flow in the Emergency Department, Healthcare Financial Management, 2008, 62(11), 104-108.

16. Egolf, B., Nail, G., Donoghue, M., Pexton, C. and Waukesha, Working to Eliminate Bottlenecks: Florida Hospital's Cardiac Cath Lab Achieves Greater Efficiency and Higher Satisfaction, Cath Lab Digest - ISSN: 1073-2667, 15(11), November 2007, 54-56.

17. Siegrist, R., Gutkin, M., Levtzion-Korach, O. and Madden, S., Improving Patient Flow in the Cath Lab, Healthcare Financial Management, 2009, 63(4), 92-98.

18. Dehmer, G.J., Hirshfeld, J.W., Oetgen, W.J., Mitchell, K., Simon, A.W., Elma, M.E., Kellett, M.A. and Brindis, R.G., CathKIT: Improving Quality in the Cardiac Catheterization Laboratory, J Am Coll Cardiol, 2004, 43, 893-899.

19. Moscucci, M., Rogers, E.K., Montoye, C., Smith, D.E., Share, D., O’Donnell, M., Maxwell-Eward, A., Meengs, W.L., De Franco, A.C., Patel, K., McNamara, R., McGinnity, J.G., Jani, S.M., Khanal, S. and Eagle, K.A., For the Blue Cross Blue Shield of Michigan Cardiovascular Consortium (BMC2), Association of a Continuous Quality Improvement Initiative with Practice and Outcomes Variations of Contemporary Percutaneous Coronary Interventions, Circulation, 2006, 113, 814-822.

20. Konopka, S., Millar, M., O'Brien, B. and Weissman, M., Reducing Delays in the Cardiac Cath Lab with Six Sigma, Isixsigma Healthcare online, 2006, available at http://healthcare.isixsigma.com, (accessed 3 May 2009).

21. Moscucci, M and Eagle, K.A., Door-to-Balloon Time in Primary Percutaneous Coronary Intervention: Is the 90-Minute Gold Standard an Unreachable Chimera?, Circulation 2006, 113, 1048-1050. 



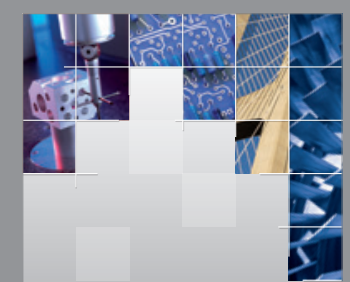

\section{Enfincering}
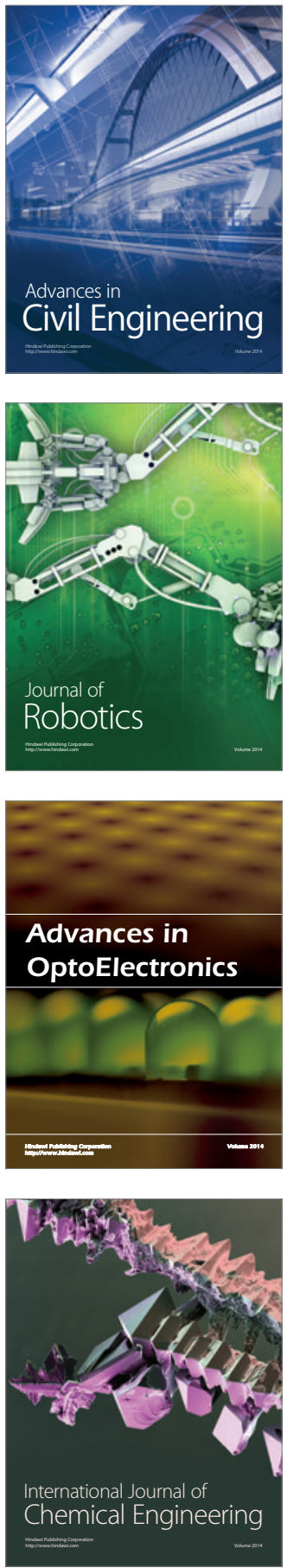

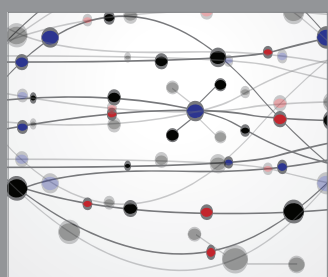

The Scientific World Journal

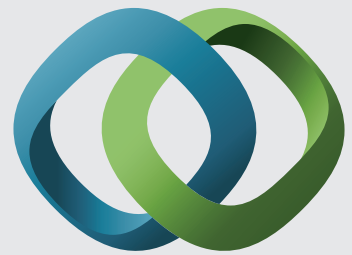

\section{Hindawi}

Submit your manuscripts at

http://www.hindawi.com
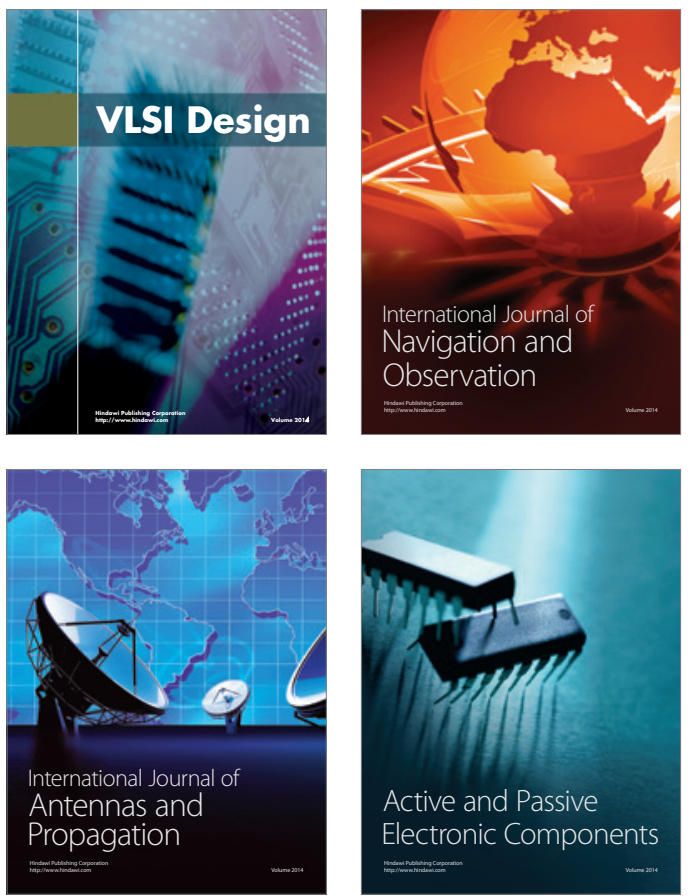
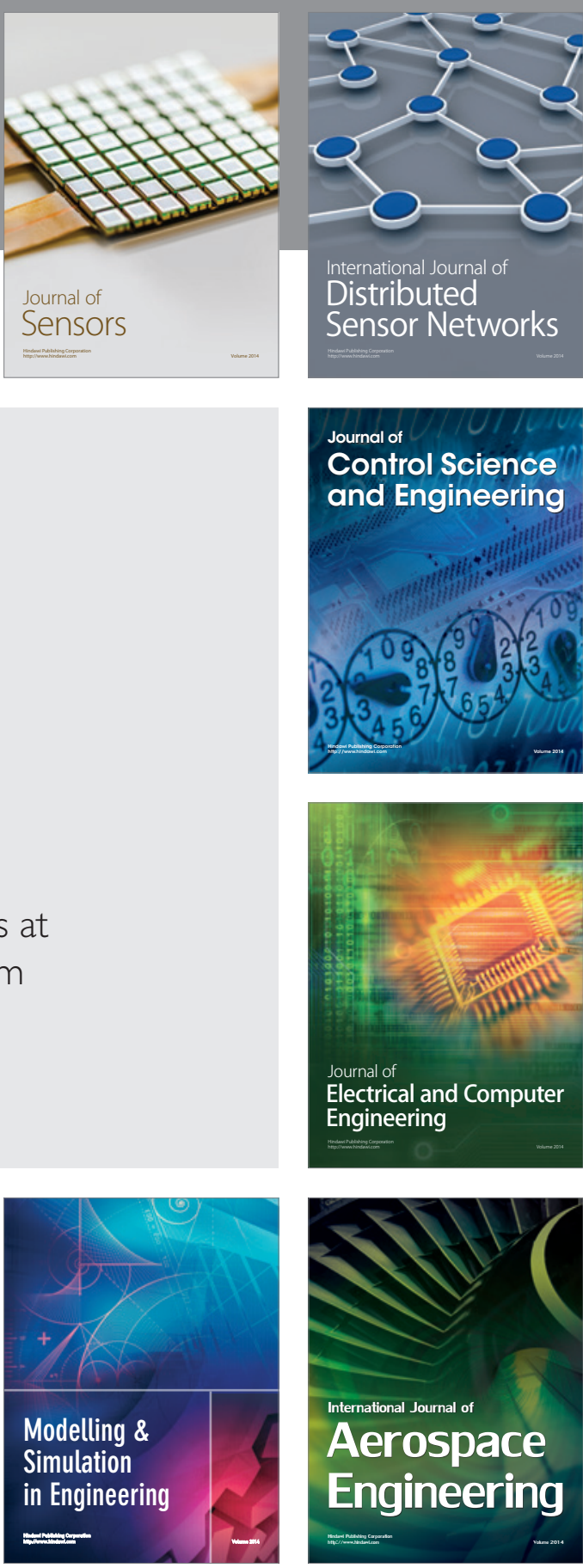

International Journal of

Distributed

Sensor Networks

Journal of

Control Science

and Engineering
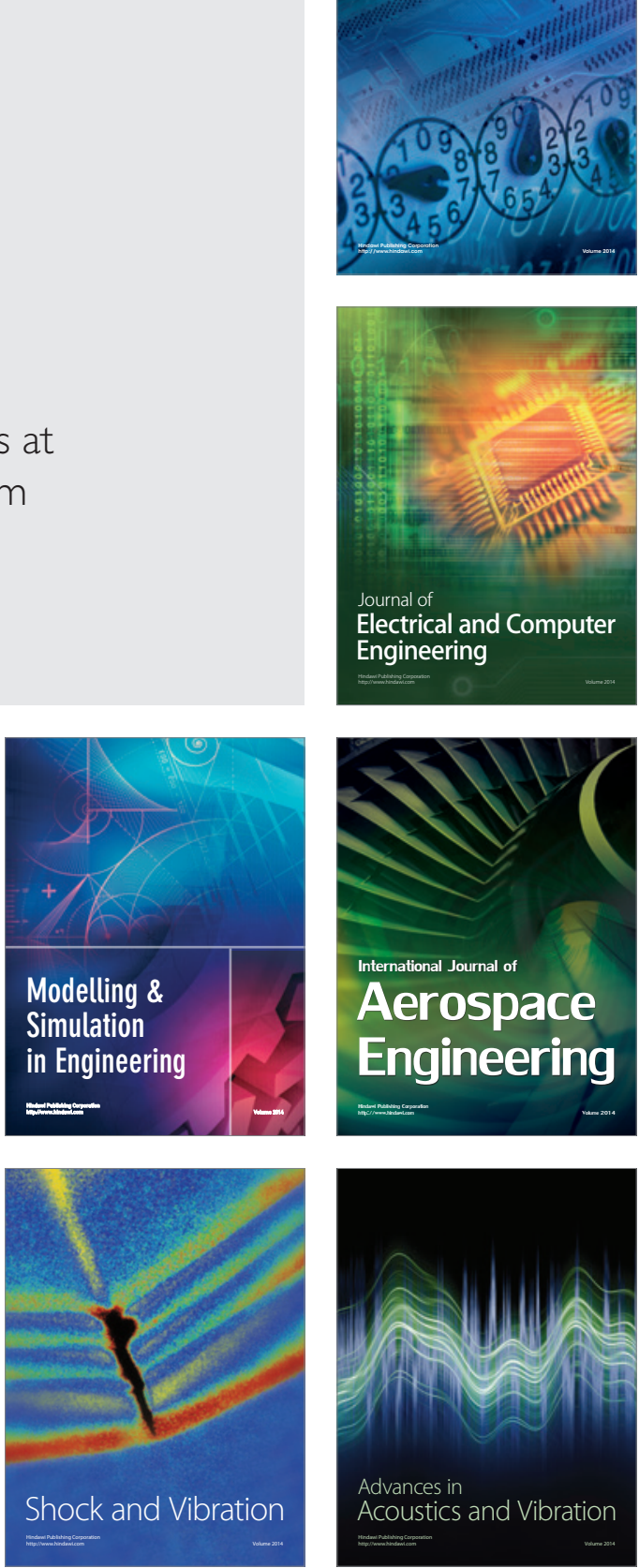